\title{
Identifying sandeel Ammodytes marinus sediment habitat preferences in the marine environment
}

\author{
Gayle J. Holland*, Simon P. R. Greenstreet, Iain M. Gibb, Helen M. Fraser, \\ Michael R. Robertson
}

Fisheries Research Services, Marine Laboratory, PO Box 101, Victoria Road, Aberdeen AB11 9DB, UK

\begin{abstract}
Sandeel abundance and sediment particle size data from 2886 grab samples collected during 14 surveys undertaken in the Wee Bankie/Marr Bank region of the north-western North Sea between 1998 and 2003 are analysed. Odds Ratio, an analysis that compares the proportion of all samples assigned to a particular sediment category, with the proportion of samples containing sandeels assigned to the same category, reveals clear patterns of either selection for, or avoidance of, seabed habitats containing varying proportions of 8 sediment particle size categories. As the proportion of Coarse Gravel, Fine Gravel, Fine Sand, Coarse Silt, Medium Silt and Fine Silt in the seabed habitat increases, sandeels show reduced selection for and increased avoidance of the habitat. Conversely, as the proportion of Coarse Sand and Medium Sand in the sediment increases, sandeels show reduced avoidance of and increased selection for the habitat. Classification Tree and Principal Components Analysis define 8 types of seabed habitat on the basis of their sediment particle size composition that vary in sandeel occupancy rate, sandeel density and the size of sandeels that occupy the habitat. Variation in sandeel density across these 8 habitat types is primarily influenced by the silt content in the sediment. Variation in the size of sandeels occupying each habitat type is mainly dictated by the coarseness of the sediment. The value of such results for the design of grab surveys intended to monitor variation in local sandeel abundance is discussed.
\end{abstract}

KEY WORDS: Ammodytes marinus $\cdot$ Sandeel $\cdot$ Habitat preference $\cdot$ Sediment particle size Resale or republication not permitted without written consent of the publisher

\section{INTRODUCTION}

Industrial fisheries, the catching of fish for industrial purposes rather than for human consumption, increased markedly in the North Sea during the 1970s, mainly due to the increased targeting of sandeel Ammodytes marinus. In recent decades annual landings of sandeels rarely dropped below 0.5 million $t$ and on occasion exceeded 1 million t (ICES 2004). The fishery for sandeels is the largest single species fishery in the North Sea. Sandeels also constitute important prey for many marine top predators, including marine mammals such as grey seals Halichoerus grypus and harbour seals Phoca vitulina (Pierce et al. 1989,1991, Tollit et al. 1997) and harbour porpoise Phocoena phocoena (Santos \& Pierce 2003), important commercial fish species, such as whiting Merlangius merlangus, cod
Gadus morhua, haddock Melanogrammus aeglefinus and mackerel Scomber scombrus (Daan 1989, Hislop et al. 1997, Pedersen 1999), and many seabird species (Furness 1990, 1996, Tasker \& Furness 1996, ICES 1998, Wanless et al. 1998). With so many marine predators dependent on sandeels, the level of exploitation of sandeels by the industrial fishery raised concerns regarding its impact on marine food webs. Annual North Sea sandeel stock assessments suggest that current levels of fishing mortality have not adversely affected spawning stock size (ICES 2004). However, sandeels in the North Sea may consist of several discrete meta-populations (a set of local populations which are either isolated from one another or have limited exchange of individuals) rather than a single homogenous stock (Proctor et al. 1998, Pedersen et al. 1999). While the population might appear healthy on a 
North Sea spatial scale because of the patchy distribution of sandeel fishing, it is possible that on a more local scale, individual sandeel meta-populations may have been over-exploited. Many sandeel fishing grounds are close to seabird colonies, and overlap in the distribution of post-settlement sandeels, seabirds at sea, and industrial fishing activity is considerable (Jensen et al. 1994, Wright \& Begg 1997), suggesting the potential for conflict. Consequently, most concern has focused on the potential impact of sandeel fishing on seabirds (Monaghan 1992, Furness \& Tasker 2000, Furness 2002, 2003). On 2 occasions in the mid-1980s on the Shetland Isles and the late 1990s in the Firth of Forth, declines in seabird breeding success appeared to be associated with increased sandeel fishing activity nearby (Monaghan et al. 1989, Hamer et al. 1991, 1993, Furness 1996, Wright 1996, Harris \& Wanless 1997). In both instances a precautionary approach was taken and the sandeel fishery in question was closed. This illustrates the importance of understanding sandeel population biology and the need to consider effects of fishing on a local scale as opposed to a North Sea wide scale.

The ability to monitor sandeel abundance in specific areas is clearly a prerequisite for local-scale management of industrial fisheries. Managers must gauge the impact of fishing on particular fishing-grounds on the abundance of local sandeel meta-populations in order to assess the risk to marine predators in the area. Assessment of variation in local sandeel population size is also a critical requirement in monitoring the effectiveness of any management action, such as local fishing moratoria. Traditionally, most information regarding the abundance of sandeels has originated from scientific monitoring of the fishery itself (Wright 1996, Furness 2002). The catch per unit effort (CPUE) data on which such assessments are based are not available prior to the fishery taking place. Managers are therefore only able to react to environmental concerns once they have occurred, rather than being in a position to take preventative measures. Commercial fishing activities do not sample sandeel populations randomly, which potentially leads to artificially high abundance indices (Hilborn \& Walters 1992). Finally, CPUE data will be unavailable from areas where the fishery has been closed, thus preventing managers from monitoring the effectiveness of specific management actions. Properly designed fisheries-independent sandeel stock-assessment surveys that can produce results within time-scales appropriate to ecosystem based management are required.

One option is to assess sandeels in the water column using acoustic pelagic trawl surveys. However, sandeels occupy both the water column and the seabed sediment in varying proportions at different times of the day and year (Macer 1966, Reay 1970, Winslade 1974a,b,c, Gauld \& Hutcheon 1990, Freeman et al. 2004), hence such survey methods will always be open to the criticism that they sample a highly variable fraction of the total population in the area. Clearly assessment methods that sample the entire population of sandeels are preferable. Sampling sandeels in the sediment presents the best opportunity for this, either during the autumn and spring or during the night in the early summer, when sandeels are not believed to be actively feeding in the water column (Macer 1966, Reay 1970, Winslade 1974a). Demersal trawls and dredges that drive the sandeels out of the sediment and into the path of the gear provide one option. However, relatively large meshes are required to prevent such gears becoming clogged with sediment, which results in relatively low catch rates. Grab sampling is the best alternative. Grabs give buried sandeels little warning of their arrival, so giving them little opportunity to escape out of the sediment. If an escape response is shown it is likely that the sandeels come upwards and thus become trapped in the grab. Sandeels are often found swimming in the water which is enclosed in the grab when a sample is collected, providing evidence of this. The grab takes a bite of the sediment back to the surface that includes any sandeels buried there. Day grabs have a bite depth of 8 to $12 \mathrm{~cm}$, depending on sediment type. Since sandeels require the presence of oxygen to survive in the sediment and the oxic layer in the seabed sediment of the North Sea is rarely more than $8 \mathrm{~cm}$ deep (Lohse et al. 1996), sandeels will normally be buried at a depth that is readily accessible to a grab (Girsa \& Danilov 1976). However, grabs suffer from the disadvantage, compared with trawls and dredges, that they only sample a very small area at a time. If grab surveys are to be useful in the provision of scientific advice for managers, grab stations must be specifically targeted at the sediment habitats most likely to be occupied by sandeels so that adequate numbers of sandeels may be sampled for a reasonable expenditure of sampling effort.

Several studies have reported on sandeel sediment habitat preferences using observations made in the field, but generally these have not provided much in the way of detail. For example, Macer (1966) and Scott (1973) both reported that sandeels occurred in areas of coarse sand, although no information on particle size was provided. Reay (1970) provided a little more detail, suggesting that sandeels showed a preference for sediments with a particle range of 0.35 to $1.35 \mathrm{~mm}$. Laboratory-based choice experiments have shown that sandeels preferred sand habitat over gravel habitat (Pinto et al. 1984), and Wright et al. (2000) demonstrated that whilst sandeels showed a strong prefer- 
ence for medium to very coarse sands, sediment habitats with a median particle size of 0.25 to $2.0 \mathrm{~mm}$, they avoided sediment habitats with a silt content of more than $10 \%$. The ease of penetration into the sediment has been considered to be an important factor in determining sediment habitat choice (Macer 1966, Reay 1970, Meyer et al. 1979, Pinto et al. 1984) and this may be associated with coarser sand and finer gravel sediments.

The field data available to date do not define sandeel seabed habitat in sufficient detail to provide an adequate basis for a useful grab survey design in conjunction with habitat mapping (Greenstreet et al. 1997). Although the laboratory based studies provide more detail of the specific habitat requirements of sandeels, their results still need to be verified with field data. Hypotheses posed by these studies, for example that the preference for coarser sands may increase with fish size (Wright et al. 2000), need to be tested. The objectives of this paper are to determine the precise sediment characteristics that define unsuitable seabed habitats, as well as various grades of suitable sandeel habitat. The results are discussed with respect to the design of grab surveys for sandeels.

\section{MATERIALS AND METHODS}

The study area was situated between latitudes $56^{\circ} 00^{\prime} \mathrm{N}$ and $56^{\circ} 30^{\prime} \mathrm{N}$ and longitudes $003^{\circ} 00^{\prime} \mathrm{W}$ and $001^{\circ} 10^{\prime} \mathrm{W}$, east of the Firth of Forth, south-east Scotland (Fig. 1). Fourteen grab surveys were carried out in spring, summer and autumn between March 1998 and October 2003 using the Scottish Fisheries RV 'Clupea' (Table 1). In the first cruise a stratified random grab survey design was adopted based on a sediment map constructed for the area using the acoustic seabed single beam classification system RoxAnn ${ }^{\odot}$ (Marine Microsystems). The Danish FRV 'Dana' undertook the initial RoxAnn survey in April 1997 (ELIFONTS 1999). The acoustic classification data collected were analysed following recognised procedures (e.g. Green- street et al. 1997, Sotheran et al. 1997). Forty-three Box Core sediment samples were used to calibrate the RoxAnn data, relating RoxAnn values (Folk 1954) sediment grades to produce a sediment map based on the same sediment categories as the British Geological Survey (BGS) North Sea sediment maps (ELIFONTS 1999) (Fig. 1).

Individual RoxAnn observations were selected as grab stations so that each grab sample could be directly related to a specific RoxAnn datum. From the full RoxAnn data set of 60979 values, records obtained

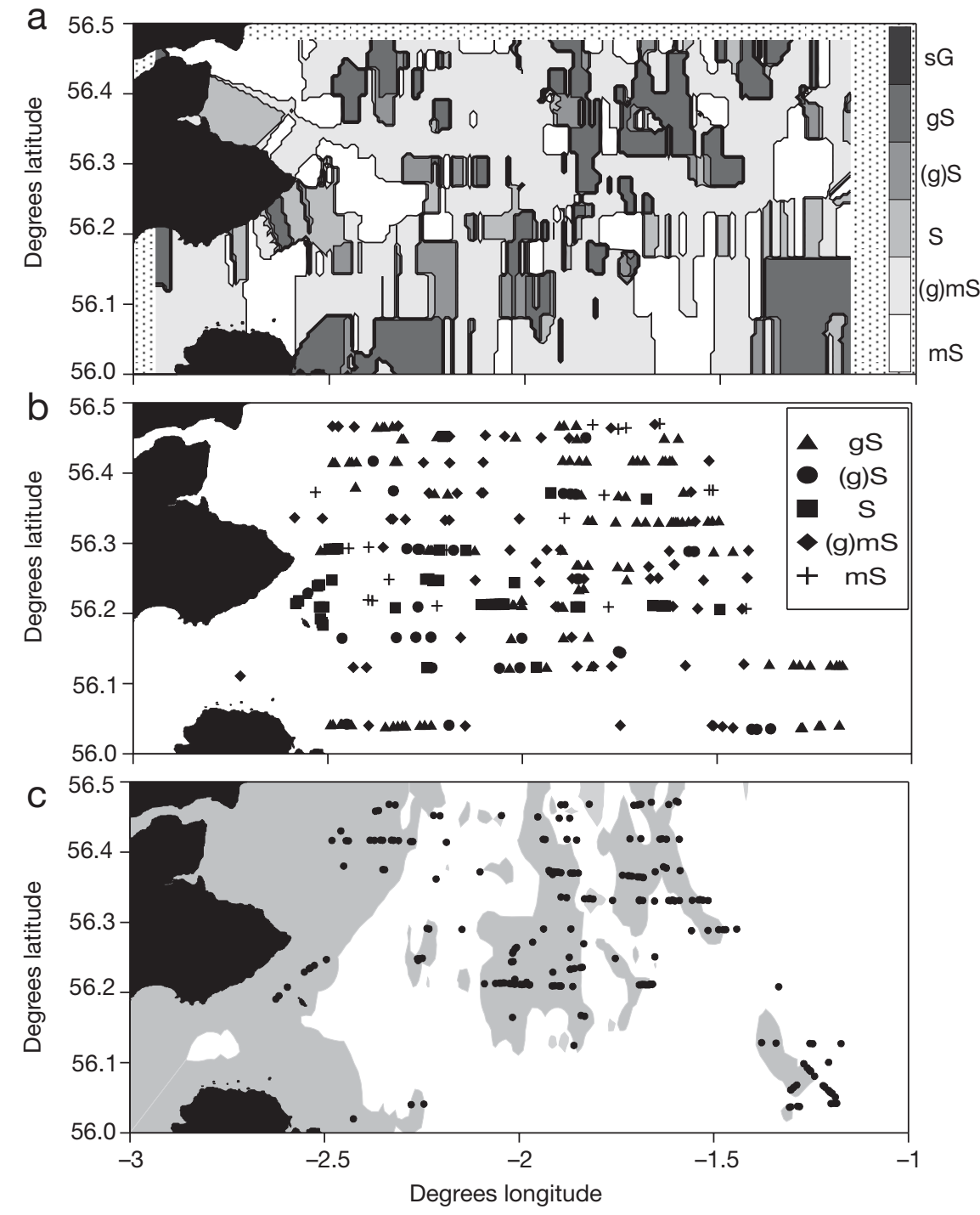

Fig. 1. (a) Preliminary habitat map derived from the 'Dana' RoxAnn data using the Folk (1954) sediment classification scheme and original stratified random grab-sampling scheme. (b) Positions of the initial 268 stations sampled in March 1998 and the type of sediment on which they were targeted are shown. sG: sandy gravel; gS: gravelly sand; (g)S: slightly gravelly sand; S: sand; (g)mS: slightly gravelly muddy sand; mS: muddy sand. (c) Grab stations sampled in subsequent grab surveys and bathymetric information (light grey shading indicates areas where water depth is $<50 \mathrm{~m}$ ) 
Table 1. Details of the sampling schedule for the 6 yr survey

\begin{tabular}{|lccc|}
\hline Cruise & $\begin{array}{c}\text { Total no. } \\
\text { samples } \\
\text { collected }\end{array}$ & $\begin{array}{c}\text { No. samples } \\
\text { containing } \\
\text { sandeels }\end{array}$ & $\begin{array}{c}\text { Total no. } \\
\text { sandeels } \\
\text { caught }\end{array}$ \\
\hline Mar 98 & 398 & 95 & 939 \\
Jun 98 & 185 & 42 & 125 \\
Oct 98 & 137 & 42 & 169 \\
Jul 99 & 188 & 75 & 481 \\
Oct 99 & 195 & 116 & 936 \\
Mar 00 & 314 & 86 & 522 \\
Jun 00 & 273 & 73 & 502 \\
Oct 00 & 164 & 57 & 554 \\
Mar 01 & 185 & 54 & 406 \\
Oct 01 & 186 & 49 & 258 \\
Mar 02 & 153 & 36 & 213 \\
Oct 02 & 173 & 56 & 266 \\
Mar 03 & 160 & 23 & 111 \\
Oct 03 & 175 & 55 & 362 \\
& & & \\
\hline
\end{tabular}

only within the first $5 \mathrm{~s}$ of each minute were extracted. This ensured that any 2 RoxAnn data that might be selected as grab stations were at least approximately $300 \mathrm{~m}$ apart (the distance covered in $1 \mathrm{~min}$ ). Sections of duplicate RoxAnn track were then deleted, again to ensure that grab stations would not be too close to one another. These exclusion processes reduced the number of available RoxAnn records to 2992 and had little effect on the proportion of RoxAnn data assigned to any particular Folk (1954) sediment category. These proportions were then used to determine the number of grab stations that should be targeted at each sediment category.

On the basis of previous experimental studies which found that sandeels avoided sediments with a high silt content (Reay 1970, Wright et al. 2000), 2 Folk (1954) sediment categories that together accounted for $67 \%$ of all the RoxAnn data, muddy sand (mS) and slightly gravelly muddy sand ((g)mS), were considered a priori to be unsuitable sandeel habitat. Three sediment categories, sand (S), slightly gravelly sand ((g)S) and gravelly sand ( $\mathrm{gS})$, considered to contain potentially suitable habitat for sandeels, accounted for the remaining $33 \%$ of the RoxAnn data. In order to achieve adequate sampling of the rarer potentially suitable habitat and to avoid over sampling the more common unsuitable habitat types, in the design of the grab sample survey, the potentially suitable sediment habitats were targeted preferentially. The proportion of grab stations directed at the 3 potentially suitable sediment categories was double the proportion of RoxAnn values assigned to each category. Conversely, the proportion of grab stations directed at RoxAnn data assigned to the 2 unsuitable sediment categories was half the proportion of RoxAnn data assigned to each of these. This resulted in a total of 87 grab stations being sited on
RoxAnn data locations assigned to the 2 unsuitable sediment categories and 181 grab stations being sited on RoxAnn data locations assigned to potentially suitable sediment categories. The required number of grab sample stations on each sediment type was selected at random from the final extraction of 2992 RoxAnn records (Fig. 1). In subsequent cruises some additional stations, selected at random from the RoxAnn data locations, were added in areas of $\mathrm{S},(\mathrm{g}) \mathrm{S}$ and $\mathrm{gS}$, and some stations, again selected at random, were deleted from $\mathrm{mS}$ and $(\mathrm{g}) \mathrm{mS}$ areas. Depending upon variation in weather conditions, up to 240 grab stations were sampled in each of the subsequent cruises using this modified stratified random design (Fig. 1). A total of 2886 valid samples were collected over the $6 \mathrm{yr}$ survey.

Samples were collected at night at each station using a Day grab sampling an area of $0.096 \mathrm{~m}^{2}$ (measurements: length $310 \mathrm{~mm}$, width of both jaws $310 \mathrm{~mm}$, depth $150 \mathrm{~mm}$ ). Generally an adequate sample was obtained at each station with the first deployment of the grab. In all, $76.3 \%$ of the grab samples were collected from within $100 \mathrm{~m}$ of the actual station position and $97.8 \%$ were within $250 \mathrm{~m}$. On recovery of the grab, a sample of the sediment was taken for analysis in the laboratory using a $32 \mathrm{~mm}$ internal diameter $120 \mathrm{~mm}$ long corer, of sufficient size to sample large gravel particles and small stones. Two cores were collected from each grab sample. To avoid losing the fine sediment material stirred loose from the main body of sediment in the grab, care was taken to include in the core samples the water lying over top of the sediment. The core samples were examined to check that no sandeels had been accidentally included. The remaining sediment was then washed through a $2 \mathrm{~mm}$ sieve in which all the sandeels were retained. All sandeels were counted and measured to the $1 / 2 \mathrm{~cm}$ below. A total of 5844 sandeels were caught during the 6 yr survey.

Sediment samples were stored frozen and, before being analysed, water was removed by freeze-drying. The samples were then shaken through a sieve stack of $8,4,2,1.4,1,0.71$ and $0.5 \mathrm{~mm}$ sieves. The material retained in each sieve was weighed in $\mathrm{g}$ to 2 decimal places. Laser granulometry, using a Malvern particle sizer with 300 and $45 \mu \mathrm{m}$ lenses, was used to determine the proportion of material which passed through the $0.5 \mathrm{~mm}$ sieve. In effect, estimates of the quantity of material which were greater than particle size classes of $353.6,250,176.8,125,88.4,63,44.2,31.3,22.1,15.6$, $11,7.8,5.5,3.9,2.7,2,1.4,1$ and $0.1 \mu \mathrm{m}$ were determined. Thus the proportion by weight of each sample belonging to 26 particle size fractions was estimated.

Folk (1954) defined 3 broad sediment classes: gravel, sand and silt. These broad grades were split into 2 or 
3 sub-categories with more restricted sediment particle size ranges (Table 2). For each sample, the percentage by weight belonging to these sediment categories was calculated. The number of samples, in particular percentile ranges for each sediment category, could therefore be determined. Generally, percentile classes spanning $5 \%$ were used. However, at the extremes of the distributions for some sediment categories, the number of grab samples assigned to individual 5\% percentile classes was too small. Here percentile classes were aggregated in order to achieve sample sizes of at least 35 grab samples in each sediment category percentile class. Conversely, for some sediment categories, particularly the silt sediments, the 0 to $5 \%$ percentile class contained a very high proportion of all the samples. Here percentile classes were sub-divided, for example, 0 to $2.5 \%, 2.5$ to $5 \%$, or to even finer resolution.

Odds Ratio (Fleiss 1981) was used to examine sandeel habitat selection within each of the 8 sediment categories. Odds Ratio is given as:

$$
\text { Odds Ratio }=\left(\mathrm{p}_{1} \cdot \mathrm{q}_{2}\right) /\left(\mathrm{p}_{2} \cdot \mathrm{q}_{1}\right)
$$

where $\mathrm{p}_{1}=$ proportion of all samples containing sandeels assigned to a given percentile class; $\mathrm{q}_{1}=$ proportion of all samples containing sandeels assigned to all other percentile classes (thus $\mathrm{p}_{1}+\mathrm{q}_{1}=$ 1); $p_{2}=$ proportion of all samples assigned to a given percentile class; $\mathrm{q}_{2}=$ proportion of all samples assigned all other percentile classes (thus $\mathrm{p}_{2}+\mathrm{q}_{2}=1$ ). This statistic has been used in the past to compare the frequencies of particular prey in the diets of predators with the frequencies available in the predator's environment. In this way, the extent to which predators were actively selecting their prey was determined (e.g. Sinclair et al. 1994, Tollit et al. 1997). In this study we use Odds Ratio to compare, for each sediment category, the frequencies of all grab samples assigned to each percentile class, with the frequencies of grab samples containing sandeels assigned to each percentile class. In this way we examine the extent to

Table 2. Particle size ranges for the 8 sediment categories used in this study

\begin{tabular}{|ll|}
\hline Sediment category & Particle size range \\
\hline Coarse Gravel & $\geq 8 \mathrm{~mm}$ \\
Fine Gravel & $\geq 2$ to $<8 \mathrm{~mm}$ \\
Coarse Sand & $\geq 710$ to $<2 \mathrm{~mm}$ \\
Medium Sand & $\geq 250$ to $<710 \mu \mathrm{m}$ \\
Fine Sand & $\geq 63$ to $<250 \mu \mathrm{m}$ \\
Coarse Silt & $\geq 16$ to $<63 \mu \mathrm{m}$ \\
Medium Silt & $\geq 3.9$ to $<16 \mu \mathrm{m}$ \\
Fine Silt & $\geq 0.1$ to $<3.9 \mu \mathrm{m}$ \\
\hline
\end{tabular}

which sandeels are selecting seabed habitats with particular sediment particle size distributions. Logarithms (base 10) of the Odds Ratio were plotted so that positive $\log _{10}$ Odds Ratios indicated preference for, or selection of, seabed habitats consisting of a particular proportion of each sediment category while negative values indicated avoidance of, or selection against, a seabed habitat.

The results from the Odds Ratio Analysis were used to define unsuitable sandeel habitat by performing chi-square tests on the 8 sediment categories and determining the degree to which each influenced the presence or absence of sandeels. The 4 most influential sediment categories were used to define the most unsuitable habitat. Because of strong covariance between the different sediment categories, Principal Components Analysis (PCA) was used to identify covarying sediment categories and to define sets of sediment categories that were independent of each other. This PCA was then incorporated into a Classification Tree Analysis (CTA) in order to reduce the number of independent variables at the first split on the TREE from 8 sediment categories, that to a greater or lesser extent were auto-correlated with one another, down to just 2 variables that were largely independent of each other. Classification trees which were computed using SYSTAT $^{\odot}$ were developed by Breiman et al. (1984) and defined various grades of suitable habitat. The method predicts membership of cases or objects in the classes of a categorical dependent variable (in this case the presence or absence of sandeels) from their measurements on one or more predictor variables (in this case sediment sample particle size characteristics). The unsuitable habitat (defined from results of Odds Ratio) was then combined with the CTA, thus giving 7 types of suitable habitat and 1 unsuitable habitat. These analyses were performed in SYSTAT $^{\odot}$ after first transforming the proportions data using an arcsine transformation, the standard method used to normalise proportions data (Zar 1974). SYSTAT ${ }^{\odot}$ uses algorithms from Breiman et al. (1984) for its splitting computations. The number of terminal nodes is determined by pruning the tree. After computing an exhaustive tree the programme eliminates nodes that do not contribute to the overall prediction.

One-way ANOVA followed by Scheffe post-hoc comparisons were used to examine the differences in densities of sandeels and the differences in the mean length of sandeels between the 8 sediment nodes. Relationships between sandeel density and siltiness of the sediment were examined using both exponential and polynomial regression models. Linear regression determined the relationship between mean sandeel length and coarseness of the sediment. 


\section{RESULTS}

Odds Ratio Analysis indicated clear selectivity trends for all 8 of the sediment particle size categories examined (Fig. 2). As the proportion of Coarse Gravel, Fine Sand, Coarse Silt, Medium Silt or Fine Silt in the seabed sediment increased, sandeels showed reduced preference and increased avoidance of the habitat. For Coarse Sand and Medium Sand, the reverse was true. For Fine Gravel a more complex relationship was observed. When the proportion of Fine Gravel in the seabed sediment was low, sandeels appeared to avoid the habitat. As the proportion of Fine Gravel increased, sandeels showed a preference for the habitat, but at the highest proportions of Fine Gravel in the sediment, the habitat was once again avoided by sandeels. The switch points $\left(\log _{10}\right.$ Odds Ratio $\left.=0\right)$ in the histograms were used to define suitable (selected) and unsuitable (avoided) ranges for the proportion of each sediment particle size category in the seabed habitat. Thus, for example, if the sediment contained less than 15\% Coarse Sand the habitat was unsuitable and was avoided by sandeels; over $15 \%$ Coarse Sand in the sediment and the habitat was selected by sandeels and therefore considered suitable. $2 \times 2$ contingency tables confirmed the significance of this seabed habitat selection by sandeels $(p<0.01$ for each of the sediment particle size categories). As a result of selection for seabed habitats characterised by particular proportions of each particle size category, variation in seabed habitat occupancy rate was also significantly related to the proportion of each particle size category in the sediment. The percentage of grab samples containing sandeels varied significantly, and predictably, with variation in the proportion of sediment particle size category in the seabed sediment (test for Linear trends in Proportions (Snedecor \& Cochran 1967), $\mathrm{p}<0.01$ in all cases (Fig. 3).

In order to define suitable and unsuitable seabed habitat for sandeels a 2stage approach was used. Firstly results from the Odds Ratio Analysis were used to define unsuitable habitat; 651 samples were identified of which only 11 contained sandeels $(1.7 \%)$. These unsuitable sediments had the following sediment characteristics: $>1 \%$ Medium Silt AND $\leq 55 \%$ Medium Sand AND $>2 \%$ Coarse Silt AND $\leq 15 \%$ Coarse Sand, (Fig. 4, TREE 1). While this analysis clearly defined the unsuitable habitat, in the form of the AND statement (unsuitable habitat must have all of the 4 sediment characteristics described above), suitable habitat was only very broadly defined, taking instead the form of an OR statement: $\leq 1 \%$ Medium Silt OR $>55 \%$ Medium Sand OR $\leq 2 \%$ Coarse Silt OR $>15 \%$ Coarse Sand (suitable habitat may have only 1 of these sediment characteristics) (Fig. 4, TREE 1). The second stage was to perform a CTA which was used to define various grades of suitable seabed habitat. Defining suitable sandeel habitat in this way is complicated by the fact that variation in any particular particle size category is unlikely to be independent of variation in other categories. PCA
Fig. 2. Results of the Odds Ratio Analysis illustrating selection or avoidance by sandeels for habitats containing different proportions of each particle size category. Histogram bar labels indicate the number of samples 
was used to address this issue. The first 2 principal components explained $78 \%$ of the variance (PC1 $43 \%$, PC2 $35 \%$ ). PC1 was strongly positively correlated with all 3 silt particle size categories (all $3 \mathrm{R}$ values $>0.92$ ), but was not correlated with any of the 5 other particle size categories. PC2 was negatively correlated with the 3 coarsest particle size categories, Coarse Gravel $(\mathrm{R}=$ $-0.71)$, Fine Gravel $(R=-0.92)$ and Coarse Sand $(R=$ $-0.78)$, and positively correlated with the 2 remaining intermediate particle size categories, Medium Sand $(R=0.68)$ and Fine Sand $(R=0.77)$. The PCA results suggest that variation in the 3 silt particle size categories was independent of variation in the other 5 sand or gravel categories. In effect, since the 3 silt categories contributed only a small fraction of the total, this left plenty of scope for independent variation in the sand and gravel components. PC1 therefore represents the siltiness of the sediment while PC2 provides an indication of particle coarseness in the sediment, with lower $\mathrm{PC} 2$ values indicating coarser sediments.

CTA defined habitats with varying suitability for sandeels, which were then ranked according to habitat preference. At the first level the Tree Analysis used the 2 principal components parameters to provide the first branch point, separating 1271 samples where PC1 <-0.315, of which 698 (54.9\%) contained sandeels and 1615 samples where PC1 $\geq-0.315$, of which only 161 contained sandeels $(10.0 \%)$. The Tree Analysis was then extended to include any possible contributions by the 2 gravel and 3 sand particle size, resulting in a Tree consisting of 7 terminal nodes (Fig. 4, TREE 2). TREES 1 and 2 were then combined to remove any samples from habitats defined as unsuitable by TREE 1 from each of the terminal nodes defined in TREE 2 (Fig. 4, TREE 3). In fact, this affected only terminal Nodes 6 and 7 in TREE 2; none of the samples defined as unsuitable in TREE 1 had been assigned to terminal Nodes 1 to 5 in TREE 2. The effect of this was to add an eighth node to TREE 2, drawing grab samples from Nodes 6 and 7 . This eighth node consisted of sediments with particle size characteristics considered to be unsuitable as sandeel seabed habitat (Fig. 4, TREE 3).
The sediment particle size characteristics of the seabed habitats in each of these 8 terminal nodes is summarised in Table 3 . In defining these habitat types in this way, PC1 values of -0.315 , for example, mean little in terms of the physical characteristics of the habitat. PC1 was strongly and linearly correlated with all 3 of the arcsine transformed proportional contributions of each of the silt particle size categories (Fig. 5). PC1 was regressed on each of the 3 arcsine transformed silt particle size categories to determine the arcsine transformed values predicted at the PC1 values of 0.124 and -0.315 that defined branching points in TREE 2 . These arcsine transformed values were then back transformed to give equivalent percentage contributions of

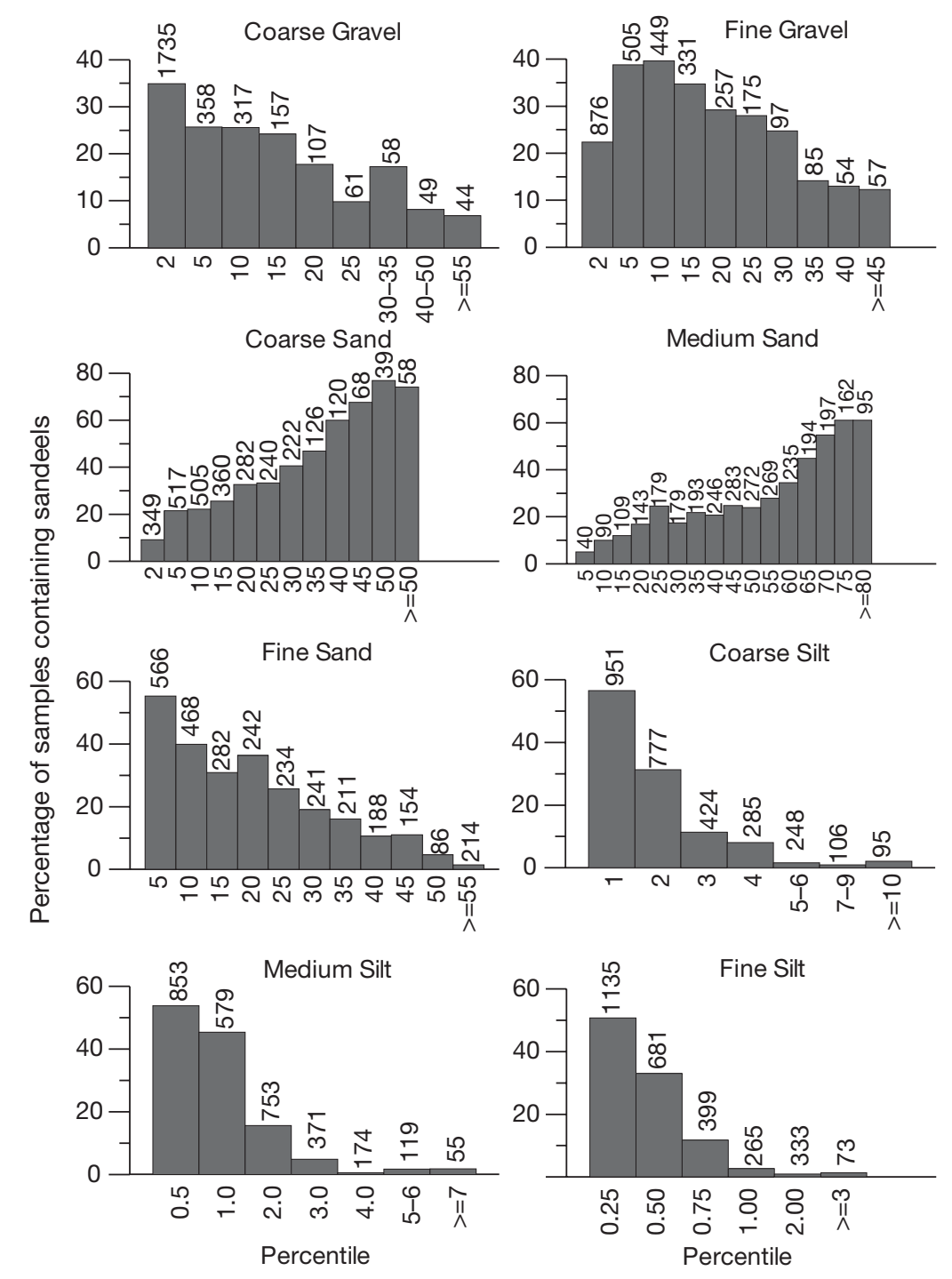

Fig. 3. Variation in the percentage of sediment samples containing sandeels with varying proportions of each of the sediment categories. Histogram bar labels indicate the number of samples 
Coarse Silt, Medium Silt and Fine Silt to the overall sediment particle size distributions (Table 4). The critical importance of silt in defining suitable sandeel habitat is underlined by these extremely low percentages. If the silt content was greater than around $4 \%$, then the sediment habitat was rarely occupied by sandeels. Silt contents in excess of this amount rendered the seabed habitat unsuitable. The terminal nodes were numbered according to their percentage occupancy
(Table 3). Not surprisingly therefore, when all samples assigned to each node were considered, the density of sandeels $\left(\right.$ no. $\mathrm{m}^{-2}$ ) also more or less ranked in node numerical order, highest in Node 1 and lowest in Node 8 (Fig. 6a). However, if grab samples containing no sandeels were excluded from this analysis, therefore in effect examining the density of sandeels in occupied seabed habitat only, significant differences between habitats were still detected (1-way ANOVA on $\log _{10}$

\section{TREE 1}
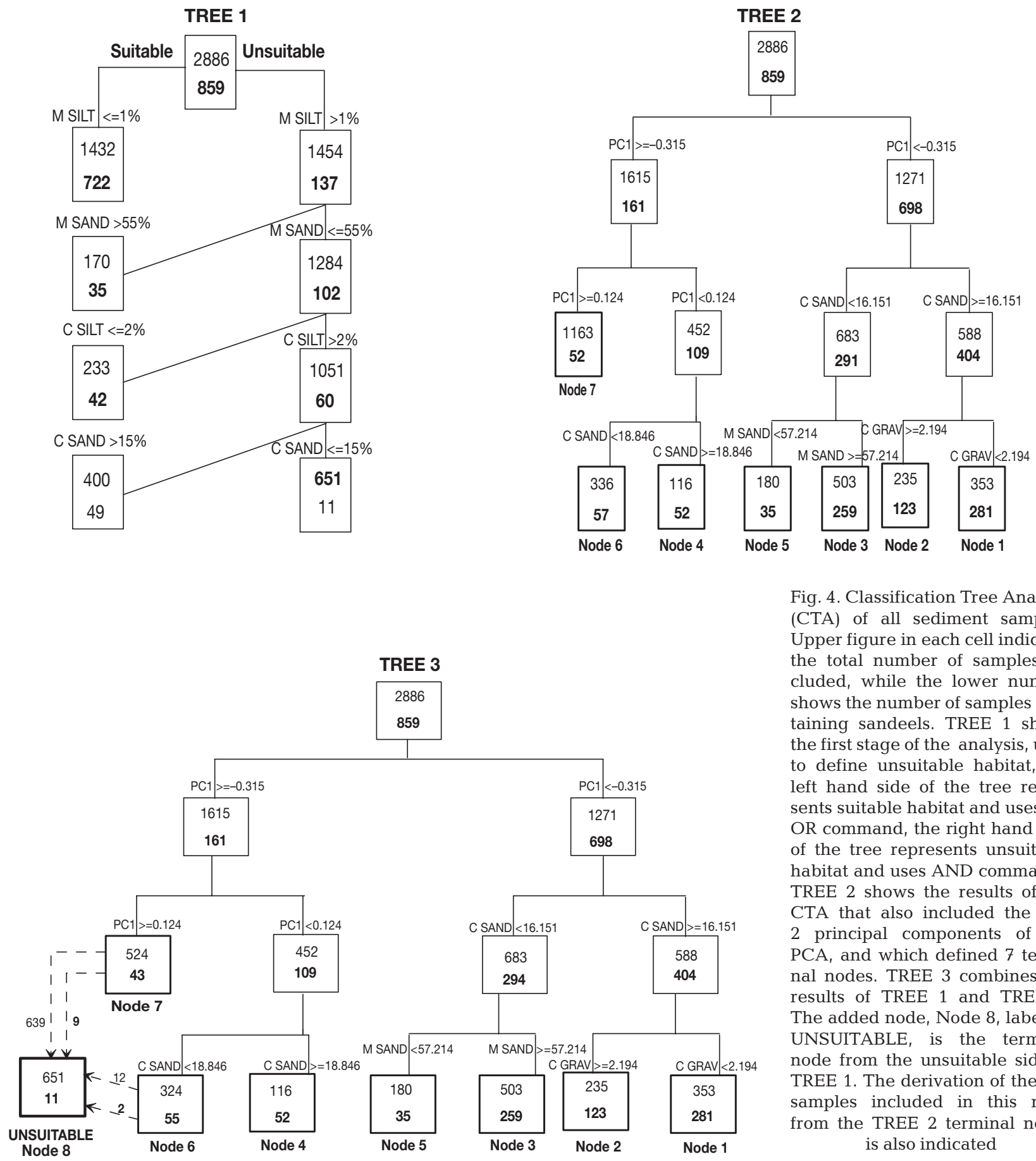

Fig. 4. Classification Tree Analysis (CTA) of all sediment samples. Upper figure in each cell indicates the total number of samples included, while the lower number shows the number of samples containing sandeels. TREE 1 shows the first stage of the analysis, used to define unsuitable habitat, the left hand side of the tree represents suitable habitat and uses the OR command, the right hand side of the tree represents unsuitable habitat and uses AND commands. TREE 2 shows the results of the CTA that also included the first 2 principal components of the PCA, and which defined 7 terminal nodes. TREE 3 combines the results of TREE 1 and TREE 2 . The added node, Node 8, labelled UNSUITABLE, is the terminal node from the unsuitable side of TREE 1. The derivation of the 651 samples included in this node from the TREE 2 terminal nodes is also indicated 
Table 3. Sediment characteristics and the occupancy rate (percentage of samples containing sandeels) for each of the 7 terminal nodes defined in TREE 2 after samples from unsuitable sediment habitats defined by TREE 1 are removed and assigned a category (US) of their own

\begin{tabular}{|c|c|c|}
\hline Node & Characteristics & $\%$ samples containing sandeels \\
\hline 1 & PC $1<-0.315$, Coarse Sand $\geq 16.151 \%$, Coarse Gravel $<2.194 \%$ & 79.6 \\
\hline 2 & PC $1<-0.315$, Coarse Sand $\geq 16.151 \%$, Coarse Gravel $\geq 2.194 \%$ & 52.3 \\
\hline 3 & PC $1<-0.315$, Coarse Sand $<16.151 \%$, Medium Sand $\geq 57.214 \%$ & 51.5 \\
\hline 4 & PC $1 \geq-0.315$, PC $1<0.124$, Coarse Sand $\geq 8.846 \%$ & 44.8 \\
\hline 5 & PC $1<-0.315$, Coarse Sand $<16.151 \%$, Medium Sand $<57.214 \%$ & 19.4 \\
\hline 6 & PC $1 \geq-0.315, \mathrm{PC} 1<0.124$, Coarse Sand $<18.846 \%$ & 17.0 \\
\hline 7 & $\mathrm{PC} 1 \geq 0.124$ & 8.2 \\
\hline \multicolumn{2}{|c|}{ US Medium Silt $>1 \%$, Medium Sand $\leq 55 \%$, Coarse Silt $>2 \%$, Coarse Sand $\leq 15 \%$} & 1.7 \\
\hline
\end{tabular}

transformed grab catches, $\mathrm{p}<0.01$ ). Thus occupied Node 1 type seabed habitat was occupied at higher sandeel densities than occupied habitat defined by the particle size characteristics of Nodes 2 to 7 (Scheffe post-hoc comparisons, $p<0.01$ in each case). Node 8 was not found to have significantly different densities of sandeels to Node 1 ; this can be explained by the very low numbers of occupied Node 8 type sediment samples, one of which had an unusually high number of sandeels present. The occupancy rate percentages in Table 3 together with the mean densities of sandeels in occupied habitat shown in Fig. 6a suggest a clear preference by sandeels for seabed habitat defined by the sediment particle size characteristics attributed to terminal Nodes 1,2 and 3. Although the density of sandeels in occupied seabed habitat defined by the sediment particle size characteristics of Nodes 4 to 8 show little difference (Fig. 6a), the percentage occupancy rates do differ (Table 3 ). This suggests that sandeels prefer Node 4 type seabed habitats over Node 5 and 6 types, which in turn are preferred over Node 7 and 8 type habitats. Sandeel density in each node seabed habitat was related to both PC1 (the principal component related to siltiness of the sediment) and to the total proportion of silt in the sample (particle size $<0.063 \mathrm{~mm}$ ) (Fig. 6). Significant relationships were observed when zero catch samples were either included in or excluded from the analysis. In both

Table 4. Percentage of each of the 3 silt particle size categories present in the sediment at PC1 values identified as branching points in TREE 2

\begin{tabular}{|lcc|}
\hline $\begin{array}{l}\text { Silt particle } \\
\text { size category }\end{array}$ & $\begin{array}{c}\text { \% silt category in the sediment } \\
\text { at PC1 values of: } \\
\text { PC1 } 1=0.124\end{array}$ \\
\hline PC1 $=-0.315$ & 2.209 \\
Medium Silt & 1.406 & 1.308 \\
Fine Silt & 0.812 & 0.440 \\
\hline
\end{tabular}

cases the relationships were curvilinear (polynomial and exponential fits were both applied) suggesting that most of the effect was at the lowest silt contents $(<2 \%)$. Above a silt content of $2 \%$, a further increase in silt content of the sediment up to $4 \%$ had little effect on the density of sandeels occupying the seabed habitat. Sandeel density in the seabed habitat was not influenced by variation in sediment particle coarseness, as indicated by PC2 (including zero catches $\mathrm{R}=-0.15$, excluding zero catches $\mathrm{R}=0.00$ ).

A preliminary examination of the length frequency distribution of sandeels caught in the grab samples showed that this was not polymodal. Instead, the presence of older aged class sandeels was indicated by an extended tail in an otherwise normal distribution. For analysis purposes therefore, sandeel lengths were $\log _{10}$-transformed to normalise the data. For presenta-

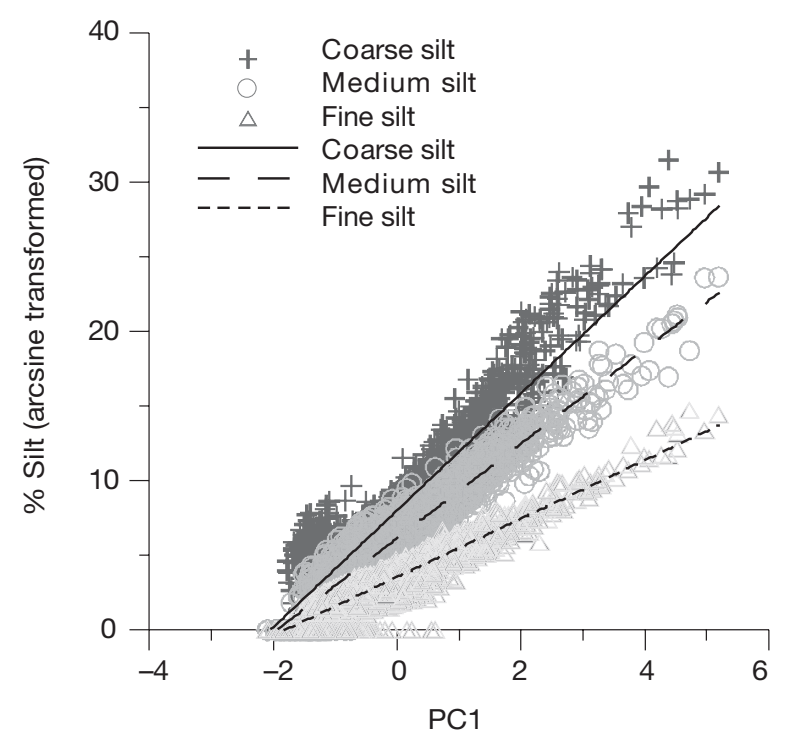

Fig. 5. Relationships between PC1 and the arcsine transformed percentage of each of the 3 silt particle size categories in the seabed sediment 


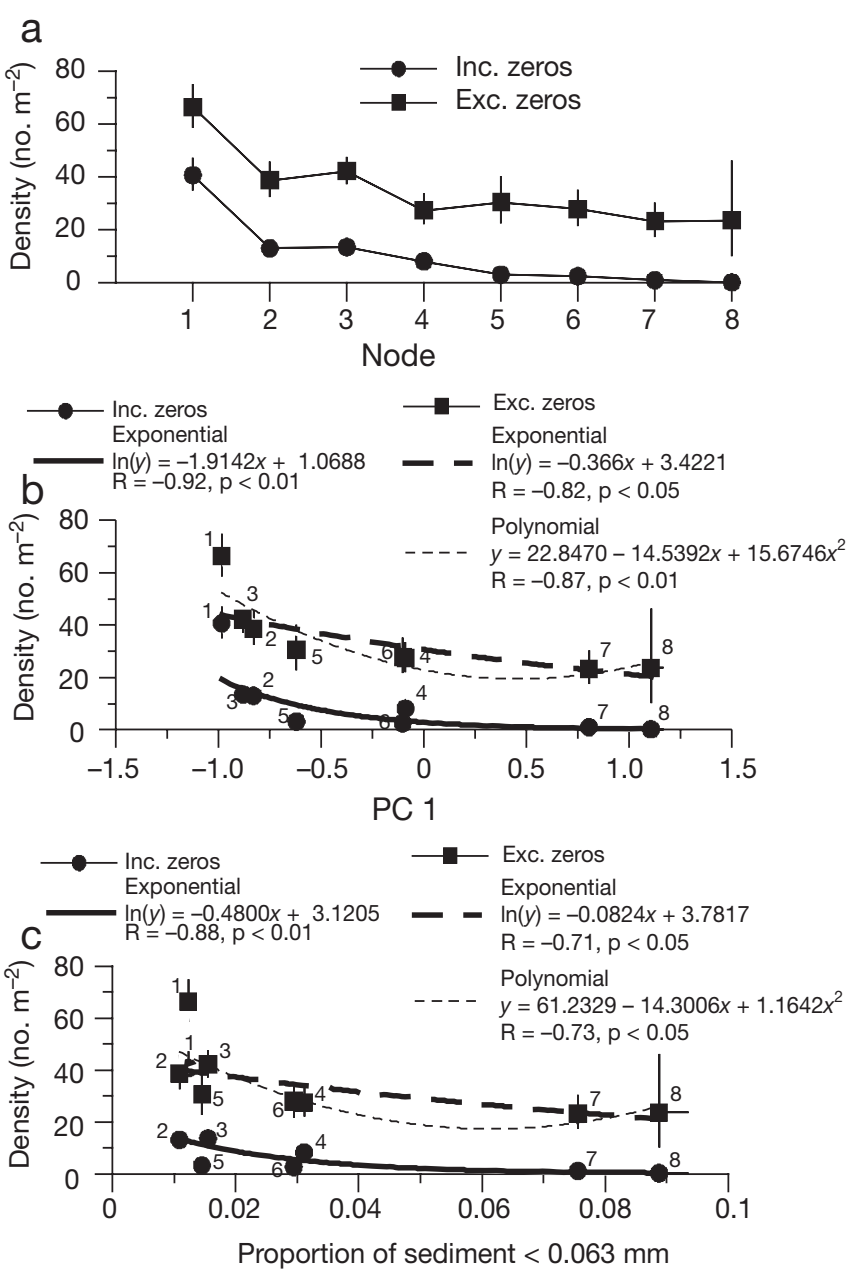

Fig. 6. (a) Mean ( \pm confidence limits) sandeel density (no. $\mathrm{m}^{-2}$ ) in each of the TREE 3 terminal nodes. Circles show the data for all the samples assigned to each node and squares exclude samples where no sandeels were caught, thereby indicating sandeel density in occupied areas of each sediment habitat. Relationships between the mean ( \pm confidence limits) density of sandeels in grab samples assigned to each sediment habitat terminal node and the mean (b) PC1 value and (c) proportion of the sediment consisting of particles $<0.063 \mathrm{~mm}$. Labels indicate the sediment habitat terminal node. Polynomial fits were not applied to the relationships including samples where no sandeels were caught because these suggested negative sandeel densities over parts of the $x$-axis range

tion purposes, all means and confidence limits were back-transformed to represent the data on the original linear scale, hence the presence of asymmetric confidence limits. The length of sandeels occupying seabed habitats characterised by the different sediment particle size composition attributed to each terminal node varied significantly (1-way ANOVA, p < 0.01, Fig. 7a). Post-hoc Scheffe comparisons indicated that mean sandeel size in Node 8 (unsuitable) type habitats was smaller than in Node $1,2,4$, and 7 type habitats $(\mathrm{p}<$ 0.01 in all cases). Sandeels in Node 7 type habitats were significantly larger than sandeels in Node 3 and 8 type habitats ( $p<0.05$ in all cases) and sandeels in Node 4 type habitats were significantly larger than sandeels in Node 3 type habitats $(\mathrm{p}<0.01)$. Sandeels in Node 3 type habitats were significantly smaller than sandeels in Node 1, 2 and 4 type habitats $(\mathrm{p}<0.01$ in all cases).

The mean size of sandeels in seabed habitats defined by the particle size characteristics of each TREE 3 terminal node was significantly related to particle size coarseness. A negative relationship between mean sandeel size and mean PC2 in each node habitat was observed, since lower PC2 values represented coarser sediments (Fig. 7b). The importance of the coarseness of the sediment particles in influencing the size of sandeels occupying each node seabed habitat was confirmed when mean sandeel size in each habitat was related to the mean proportion of the sediment consisting of particles $\geq 0.710 \mathrm{~mm}$. Again a significant relationship was observed, but in this instance, the relationship was positive (Fig. 7c). No significant relationship was found between mean sandeel length and mean PC1 values in each node seabed habitat $(\mathrm{R}=-0.28)$.
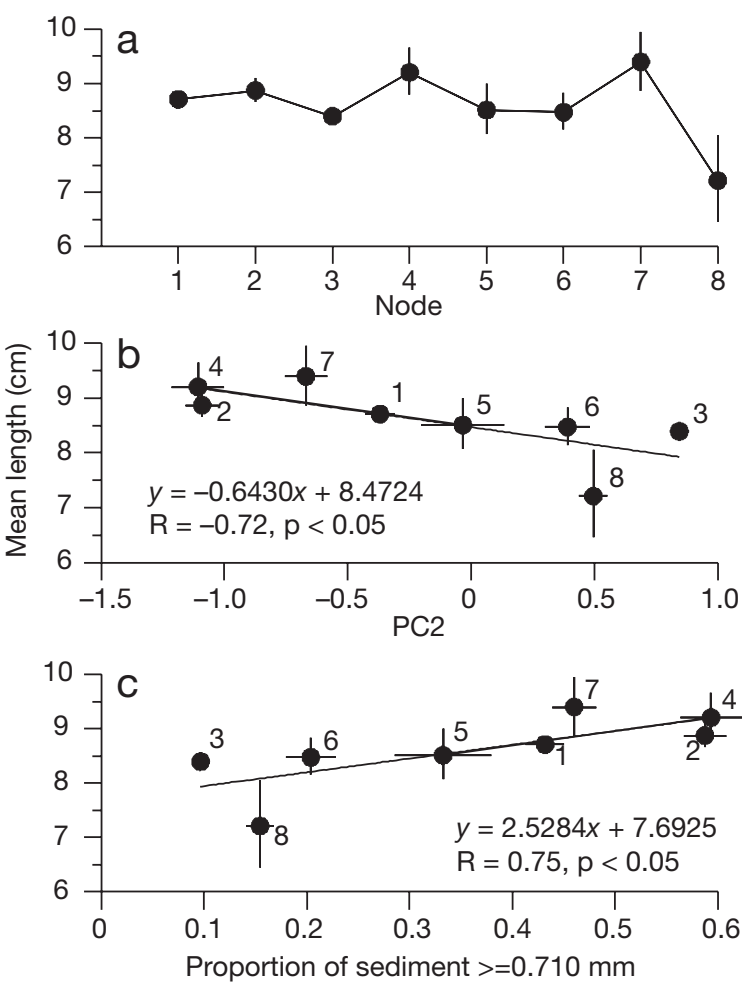

Fig. 7. (a) Mean ( \pm confidence limits) length of sandeels in grab samples assigned to each sediment habitat terminal node. Relationships between the mean ( \pm confidence limits) length of sandeels in grab samples assigned to each sediment habitat terminal node and the mean (b) PC1 value and (c) proportion of the sediment consisting of particles $\geq 0.710 \mathrm{~mm}$. Labels indicate sediment habitat terminal node 


\section{DISCUSSION}

Grab surveys provide a useful method for investigating sandeel habitat preferences in the field. The high number of samples analysed during this study has provided a detailed description of the seabed sediments which sandeels utilise. Odds Ratio Analysis indicates a strong preference for seabed habitats containing a high proportion of medium and coarse sand (particle size 0.25 to $2 \mathrm{~mm}$ ), the same particle size range preferences reported by Wright et al. (2000). Other studies have also indicated that sandeels occupy areas of coarse sand, although information on particle size is limited (Macer 1966, Scott 1973). Perhaps even more critical than the level of coarse and medium sand in the sediment is the fraction of silt. CTA determined that those sediments with the lowest silt concentrations (or lowest PC1 values) were the most likely to contain sandeels (Nodes 1, 2 and 3). Although Node 5 was on the same primary branch of the Tree as Nodes 1, 2 and 3 and therefore had low silt content, the fractions of coarse and medium sands were also low, making this sediment type less desirable. Node 4, on the other hand, had a higher silt element than Node 5, although still less than $4 \%$, but Node 4 had a much greater likelihood of containing sandeels because of the higher fractions of coarse sand. It therefore appears to be a combination of low silt concentrations and high fractions of medium and coarse sand that determines which sediments are suitable for sandeel occupancy.

Avoidance of silt rich sediments by sandeels has previously been reported both in the field (Macer 1966, Reay 1970, Meyer et al. 1979, Wright et al. 2000) and experimentally (Pinto et al. 1984, Wright et al. 2000). Wright et al. (2000) reported that sandeels were not found in field samples where the silt content in the sediment was greater than $10 \%$. They also noted that sandeel densities decreased as the silt fraction increased from 0 to $10 \%$. Our data would suggest that the effect of silt content on the suitability of the seabed habitat is even more critical than these earlier data would suggest. Below a silt content of $2 \%$ a high percentage of the habitat was occupied and densities were high. In seabed habitats with a silt content of between 2 and $4 \%$ sandeel density was independent of variation in the proportion of silt, but the occupancy rate continued to decline. Both the occupancy and the density of sandeels in seabed habitats containing more than $4 \%$ silt was extremely low. Furthermore, the mean length of those sandeels found in unsuitable seabed habitat (Node 8 seabed habitat) was lower (more than $1 \mathrm{~cm}$ smaller on average) than the sandeels observed in all 7 of the suitable node habitats.

The fact that sandeels do not maintain permanent burrow openings, and therefore have to ventilate their gills with interstitial water, explains why they do not occupy silt rich sediments. The fine particles could clog their gills, inhibiting respiration (Scott 1973, Meyer et al. 1979, Pinto et al. 1984). If the interstitial spaces between sand and gravel particles were occupied by silt particles there would be less space for water and the rate of exchange of interstitial water would be lower. The oxygen content in the sediment interstitial spaces would be used up more quickly and replenished at a lower rate. Lohse et al. (1996) found that oxygen concentrations differed greatly between sandy sediments and those with a high silt content. In the sandy sediment the oxygen concentration in the top $16 \mathrm{~mm}$ was almost identical to the values found in the overlying water, and the oxic zone extended down to $45 \mathrm{~mm}$. The depth of the oxic zone in the siltiest sediments was only $0.5 \mathrm{~mm}$. In a closely related species Ammodytes hexapterus, oxygen tensions lower than $30 \mu \mathrm{mol} \mathrm{dm}^{-3}$ at summer temperatures $\left(12^{\circ} \mathrm{C}\right)$, or $16 \mu \mathrm{mol} \mathrm{dm}{ }^{-3}$ at winter temperatures $\left(5^{\circ} \mathrm{C}\right)$, could not be tolerated (Quinn \& Schneider 1991). Many studies have also shown that sandeels require well flushed, tidally active areas (Macer 1966, Meyer et al. 1979, Pinto et al. 1984, Wright et al. 2000). Wright et al. (1998) reported that the areas where most $A$. marinus occur in sediments have current flows of $>0.6 \mathrm{~ms}^{-1}$. Sandeels are known to prefer depths of 30 to $70 \mathrm{~m}$, although they occur between depths of 15 and $120 \mathrm{~m}$ (Wright et al. 1998). Depth was not used as a parameter to determine suitable habitat in this study as nearly all (99\%) of the samples collected fell within the 30 to $70 \mathrm{~m}$ depth range.

Wright et al. (2000) suggested that larger sandeels would prefer coarser sediments. This speculation was confirmed in the present study. A possible explanation for this relationship could be the ease of penetration into the sediment. However, shear-stress experiments indicated that penetrability should not deter sandeels from entering fine sand, coarse sand, gravel or silt (Pinto et al. 1984). Alternatively, oxygen requirements may once again underpin this relationship. Larger sandeels are likely to require more oxygen, which will be more readily available in coarser sediments where interstitial spaces are larger and more readily flushed. The Odds Ratio analysis indicated that sandeels tended to avoid seabed habitats containing a high proportion gravel sized particles in the sediment. Although Pinto's et al. (1984) data suggest that sandeels are capable of penetrating such habitats, and indeed the data presented here show that on occasion sandeels do occupy high gravel content seabed habitat, the effort and time required to enter this type of sediment may be too costly (P. J. Wright pers. comm.).

Closure of the sandeel fishery on the Wee Bankie and Marr Bank in 2000 has resulted in an increase in 
the abundance of sandeels in the area. Reduced fishing mortality has also led to increased survival rates resulting in a higher proportion of older, and consequently larger, fish in the population (S. P. R. Greenstreet unpubl. data). Since 2 separate sediment parameters appear independently to influence the density of sandeels (sediment siltiness) and the size of sandeels (sediment coarseness) in the seabed habitat, change in the mean size of fish in the sandeel population may result in subtle changes in the perceived habitat preference ranking.

Previous studies have suggested that sandeels occupy seabed habitat following an ideal free type distribution (Fretwell \& Lucas 1970, Partridge 1978). This suggests that the most favourable habitats will be occupied preferentially. Sandeels removed from such areas by fishing will be replenished by fish from more marginal habitats. Thus, the preferred habitat will remain occupied and more marginal habitats will become vacated as a consequence of reduced population size (Wright 1996). In this study, several quite distinct habitat types have been identified and clear preferences for one type over another have been demonstrated. The data were collected over a 6 yr period during which the sandeel fishery in the area was closed and large changes in sandeel abundance have resulted. The potential to test habitat preference and occupation rules with these data is therefore high.

Sandeel catchability in grabs is higher than in any other sandeel sampler used to date. That is to say, they provided the highest estimates of point density (up to an order of magnitude greater than, for example, dredge sampling, S. P. R. Greenstreet \& G. J. Holland unpubl. data). There is some evidence that Day grabs sample different volumes of sediment depending on the sediment type. Tyler \& Shackley (1978) found that the Day grab sampled a significantly greater volume of sediment on hard sand than on muddy sand. It is believed, however, that this is unlikely to influence results in this study as most samples containing sandeels come from a fairly narrow sediment type range which will result in nominal differences in the volume of sediment sampled. The only bias might occur in the coarser end of the range of sediments suitable to sandeels as the grab sometimes fails to obtain a sufficient sample where the ground is very hard. These samples cannot be used in the analysis, and therefore, this habitat type may be undersampled. Thus grab surveys have the potential to provide the fisheries independent abundance estimates required by managers if they are obliged to regulate local fisheries in real-time. Their main drawback lies in the small overall area sampled and the consequently low total catches. This study has demonstrated that sandeels show clear preferences for particular types of seabed habitat. When combined with seabed habitat mapping, grab survey effort can therefore be directed at only those areas where sandeel seabed habitat is located. Furthermore, analysis of the sediment samples collected with each grab enables valid samples to be identified. Thus grab samples that contain no sandeels can be partitioned into 2 groups: samples from unsuitable habitat and samples from unoccupied suitable habitat. Only the latter should be included in estimating mean sandeel density, and the estimate obtained is the estimate of sandeel density in suitable habitat. By excluding all zero catches from unsuitable habitat, the variance around the mean density estimate is markedly reduced. Assuming that the actual area of suitable habitat remains unchanged from survey to survey, this density estimate becomes an indicator of change in the abundance of sandeels in the region.

Even the most suitable sandeel habitats often render zero-catch samples. There are 2 reasons for this. Firstly it is unlikely that all the most suitable habitat will be fully occupied by sandeels. If one assumes that the population is below the area's carrying capacity, and that individual animals are distributed across the suitable habitat following an ideal free type distribution, then it is inevitable that some potentially suitable habitat, albeit towards the lower end of the quality range, will be unoccupied. Secondly, the grab samples an area of only approximately $0.1 \mathrm{~m}^{2}$, thus a sandeel density of $10 \mathrm{~m}^{-2}$ is necessary if the grabs are to achieve a catch of, on average, 1 fish per sample. Even then, some samples will contain zero fish and others will hold more than 1. Conversely, low densities and low occupancy rates were recorded in the Node 8 type seabed habitat, considered here to represent seabed habitat that is unsuitable for sandeels. In these instances it is possible that the grab samples were obtained from sediments that were only just outside the parameters of a suitable seabed habitat. An alternative explanation is that animals constantly need to sample their environment in order to assess the quality of the habitat and make their choice. The sandeels caught in samples assigned to Node 8 may simply have made a poor choice.

Acknowledgements. This work was funded by The Scottish Executive and The Commission of the European Communities (EU CFP Project Q5RS-30864). We thank the masters and crew of FRV 'Clupea'. P. J. Wright provided valuable information and W. R. Turrell provided useful comments on an early draft of the manuscript.

\section{LITERATURE CITED}

Breiman L, Friedman JH, Olshen RA, Stone CJ (1984) Classification and regression trees. Wadsworth International Group, Belmont 
Daan N (1989) Database report of the stomach sampling project 1981. ICES Coop Res Rep 164:1-144

ELIFONTS (1999) The effect of large-scale industrial fisheries on non-target species. Final report on contract 95/78 to DGXIV Chapter 2

Fleiss JL (1981) Statistical methods for rates and proportions. John Wiley \& Sons, London

Folk RL (1954) The distinction between grain size and mineral composition in sedimentary rock nomenclature. J Geol 62: 344-359

Freeman S, Mackinson S, Flatt R (2004) Diel patterns in the habitat utilisation of sandeels revealed using integrated acoustic surveys. J Exp Mar Biol Ecol 305:141-154

Fretwell SD, Lucas HL (1970) On territorial behaviour and other factors influencing habitat distribution in birds. Acta Biotheoretica 19:16-36

Furness RW (1990) A preliminary assessment of the quantities of Shetland sandeels taken by seabirds, seals, predatory fish and the industrial fishery in 1981-83. Ibis 132: 205-217

Furness RW (1996) A review of seabird responses to natural or fishery-induced changes in food supply. In: Greenstreet SPR, Tasker ML (eds) Aquatic predators and their prey. Fishing News Books, Blackwell Science, Oxford, p 166-173

Furness RW (2002) Management implications of interactions between fisheries and sandeel-dependent seabirds and seals in the North Sea. ICES J Mar Sci 59:261-269

Furness RW (2003) Impacts of fisheries on seabird communities. Sci Mar 67:33-45

Furness RW, Tasker ML (2000) Seabird-fishery interactions: quantifying the sensitivity of seabirds to reductions in sandeel abundance, and identification of key areas for sensitive seabirds in the North Sea. Mar Ecol Prog Ser 202: 253-264

Gauld JA, Hutcheon R (1990) Spawning and fecundity in the Lesser Sandeel Ammodytes marinus (Raitt) in the northwestern North Sea. J Fish Biol 36:611-613

Girsa II, Danilov AN (1976) Defensive behaviour of sandlance (Ammodytes hexarterus) of the White Sea. J Ichthyol 16: 862-865

Greenstreet SPR, Tuck ID, Grewar GN, Armstrong E, Reid DG, Wright PJ (1997) An assessment of the acoustic survey technique, RoxAnn, as a means of mapping seabed habitat. ICES J Mar Sci 54:939-959

Hamer KC, Furness RW, Caldow RWG (1991) The effects of changes in food availability on the breedeing ecology of Great Skuas in Shetland. J Zool 223:175-188

Hamer KC, Monaghan P, Uttley JD, Walton P, Burns MD (1993) The influence of food supply on the breeding ecology of kittiwakes in Shetland. Ibis 135:255-263

Harris MP, Wanless S (1997) Breeding success, diet and brood neglect in the kittiwake (Rissa tridactyla) over an 11 year period. ICES J Mar Sci 54:615-623

Hilborn R, Walters CJ (1992) Quantitative fisheries stock assessment. Choice dynamics and uncertainty. Chapman \& Hall, London

Hislop J, Bromley PJ, Daan N, Gislason H and 5 others (1997) Database report of the stomach sampling project, 1991. ICES Coop Res Rep 219:1-421

ICES (1998) Report of the working group on seabird ecology. ICES Counc Meet Pap 1998 C:5:1-37

ICES (2004) Report of the working group on the assessment of demersal stocks in the North Sea and Skagerrak. ICES Counc Meet Pap 2004 ACFM:07:1-555

Jensen H, Tasker ML, Coull K, Emslie D (1994) A comparison of the distribution of seabirds and prey fish stocks in the
North Sea and adjacent areas. European Union Report 92/3501

Lohse L, Epping EHG, Helder W, Vanraaphorst W (1996) Oxygen pore water profiles in continental shelf sediments of the North Sea: turbulent versus molecular diffusion. Mar Ecol Prog Ser 145:63-75

Macer CT (1966) Sandeels (Ammodytidae) in the south-western North Sea: their biology and fishery. Ministry of Agriculture, Fisheries and Food: Fishery Investigations Series II, Vol XXIV, No. 6, HM Stationery Office, London

Meyer TL, Cooper RA, Langton RW (1979) Relative abundance, behaviour and food habits of the American Sand Lance. Ammodytes americanus, from the Gulf of Maine. Fish Bull 77:243-254

Monaghan P (1992) Seabirds and sandeels: the conflict between exploitation and conservation in the northern North Sea. Biodiversity Conserv 1:98-111

Monaghan P, Uttley JD, Burns MD, Thaine C, Blackwood J (1989) The relationship between food supply, reproductive effort, and breeding success in Arctic terns Sterna paradisaea. J Anim Ecol 58:261-274

Partridge L (1978) Habitat selection. In: Krebs JR, Davies NB (eds) Behavioural ecology: an evolutionary approach. Blackwell Scientific Publications, Oxford, p 351-376

Pedersen J (1999) Diet comparison between pelagic and demersal whiting in the North Sea. J Fish Biol 55:1096-1113

Pedersen SA, Lewy P, Wright P (1999) Assessments of the Lesser Sandeel (Ammodytes marinus) in the North Sea based on revised stock divisions. Fish Res 41:221-241

Pierce GJ, Boyle PR, Thompson PM (1989) Diet selection by seals. In: Barnes M, Gibson RN (eds) Trophic relationships in the marine environment. Proceedings of the 24th European Marine Biology Symposium, Aberdeen University Press, Aberdeen

Pierce GJ, Thompson PM, Miller A, Diack JSW, Miller D, Boyle PR (1991) Seasonal variation in the diet of common seals (Phoca vitulina) in the Moray Firth area of Scotland. J Zool 223:641-652

Pinto JM, Pearson WH, Anderson JW (1984) Sediment preferences and oil contamination in the Pacific Sand Lance Ammodytes hexapterus. Mar Biol 83:193-204

Proctor R, Wright PJ, Everitt A (1998) Modelling the transport of larval sandeels on the north-west European Shelf. Fish Oceanogr 7:347-354

Quinn T, Schneider DE (1991) Respiration of the teleost fish Ammodytes hexapterus in relation to its burrowing behaviour. Comp Biochem Physiol A 98:71-75

Reay PJ (1970) Synopsis of biological data on North Atlantic sandeels of the genus Ammodytes. Fisheries Synopsis No. 82. Food and Agriculture Organisation of the United Nations, Rome

Santos MB, Pierce GJ (2003) The diet of Harbour porpoise (Phocoena phocoena) in the Northeast Atlantic. Oceanogr Mar Biol 41:355-390

Scott JS (1973) Food and inferred feeding behaviour of Northern Sand Lance Ammodytes dubius. J Fish Res Board Can 30:451-454

Sinclair E, Loughlin T, Pearcy W (1994) Prey selection by Northern Fur Seals (Callorhinus ursinus) in the Eastern Bering Sea. Sea Fish Bull 92:144-156

Snedecor GW, Cochran WG (1967) Statistical methods. Iowa State University Press, Ames, IA

Sotheran IS, Foster-Smith RL, Davies J (1997) Mapping of marine benthic habitats using image processing techniques within a raster based geographic information system. Estuar Coast Shelf Sci 44(Suppl A):25-31

Tasker ML, Furness RW (1996) Estimation of food consump- 
tion by seabirds in the North Sea. In: Hunt GL, Furness RW (eds) Seabird/fish interactions, with particular reference to seabirds in the North Sea. ICES Coop Res Rep No. 216

Tollit DJ, Greenstreet SPR, Thompson PM (1997) Prey selection by Harbour seals, Phoca vitulina, in relation to variations to prey abundance. Can J Zool 75:1508-1518

Tyler P, Shackley SE (1978) Comparative efficiency of the day grab and Smith-McIntyre grabs. Estuar Coast Shelf Sci 6: $439-445$

Wanless S, Harris MP, Greenstreet SPR (1998) Summer sandeel consumption by seabirds breeding in the Firth of Forth, south-east Scotland. ICES J Mar Sci 55:1141-1151

Winslade P (1974a) Behavioural studies of the Lesser Sandeel Ammodytes marinus (Raitt) I. The effect of food availability on activity and the role of olfaction in food detection. J Fish Biol 6:565-576

Winslade P (1974b) Behavioural studies of the Lesser Sandeel Ammodytes marinus (Raitt). II. The effect of light intensity on activity. J Fish Biol 6:577-586

Editorial responsibility: Howard I. Browman (Associate Editorin-Chief), Storebø, Norway
Winslade P (1974c) Behavioural studies on the Lesser Sandeel Ammodytes marinus (Raitt) III. The effect of temperature on activity and the environmental control of the annual cycle of activity. J Fish Biol 6:587-599

Wright PJ (1996) Is there a conflict between sandeel fisheries and seabirds? A case study at Shetland. In: Greenstreet SPR, Tasker ML (eds) Aquatic predators and their prey. Fishing News Books, Blackwell Science, Oxford, p 154-165

Wright PJ, Begg GS (1997) A spatial comparison of Common Guillemots and sandeels in Scottish Waters. ICES J Mar Sci 54:578-592

Wright PJ, Pedersen SA, Donald L, Anderson C, Lewy P, Proctor R (1998) The influence of physical factors on the distribution of Lesser Sandeels and its relevance to fishing pressure in the North Sea. ICES Counc Meet Pap 1998/AA:3

Wright PJ, Jensen H, Tuck I (2000) The influence of sediment type on the distribution of the Lesser Sandeel, Ammodytes marinus. J Sea Res 44:243-256

Zar JH (1974) Biostatistical analysis. Prentice-Hall, Englewood Cliffs, NJ

Submitted: February 2, 2005; Accepted: June 16, 2005 Proofs received from author(s): November 7, 2005 